\title{
The Interaction System of the Main Participants of Medical Tourism
}

\author{
Zhanna Grigorieva ${ }^{1}$, Oksana Mineva ${ }^{2,}$, and Elena Gadzhieva ${ }^{3 *}$ \\ ${ }^{1}$ Sochi State University, Department of Tourism and Service, Chair of Hotel and Restaurant Business, \\ 354000 Sochi, Russian Federation \\ ${ }^{2}$ Astrakhan State University, Department of Tourism and Service, Chair of Management, 414056 \\ Astrakhan, Russian Federation \\ ${ }^{3}$ Astrakhan State University, Department of Tourism and Service, Chair of Management, 414056 \\ Astrakhan, Russian Federation
}

\begin{abstract}
To develop an efficient medical tourism system, it is currently necessary to identify the main participants in the system and clearly define their activities and interactions. The article determines the main participants in the system of medical tourism organization, describes their characteristics in terms of functions and objectives, and proposes the organisation concept of the interaction with international medical institutions and the scheme of the interaction between the main participants of medical tourism. The authors consider the main trends and prospects of the development of medical tourism on the basis of digital platform enabling to render the services for search and provision of quality medical services.
\end{abstract}

Medical tourism, both abroad and in Russia, has great potential. Over the recent years, medical tourism in Russia has been in high demand, mainly because of the reasonably high quality of provided medical services and relative financial affordability. This is facilitated by the support of the government of the Russian Federation and the achievements of domestic medicine which have been acknowledged throughout the world. The article describes the mechanism of the interaction between the participants of medical tourism in terms of the system participants' positions, their objectives and interaction scheme.

The structure of medical tourism in the areas of entry and departure with consideration to the crisis, sanctions, devaluation of the national currency and other factors has changed quite significantly over the recent years.

Under global and tough competition, such a phenomenon as medical tourism makes the entire medicine field develop at a rapid pace, adopting new advanced technologies in patients' treatment processes, as well as improving the quality of patient care.

Owing to the development of this direction and ambition of countries for becoming leaders in any of the segments of medical tourism, active advertising activities and largescale events to attract patients are being carried out.

\footnotetext{
* Corresponding author: arutunyan1109@mail.ru
} 
According to the Global Wellness Institute, the health tourism market showed a $6 \%$ increase in travel ( $\$ 524.4$ million) in 2013 reaching the turnover of $\$ 438.6$ billion which made $13.7 \%$ of the global tourism market.

The foreign tourists spent $65 \%$ more on health-improvement and domestic tourists did 1.5 times more than other target groups of tourists [1].

However, the annual increase in outbound tourism is quite high, i. e., about $30 \%$ annually. A social portrait of the tourists can be described as follows: they are middle-class people with high income at the age of 40-65; there are more women than men among them; their average stay abroad for treatment lasts for 12-18 days [2].

Consequently, the development of inbound medical tourism in Russia can directly depend on the following factors:

- a lower price for tourist medical services than in developed foreign countries,

- highly qualified medical specialists in Russia in various fields of medicine,

- availability of recreational resources for rehabilitation after treatment procedures.

The national currency weakness contributes to these trends too. So, when a complete clinical examination in Germany costs 2,000 euros, a similar examination in leading Russian medical institutions is no more than 500 US dollars [3].

To create an effective medical tourism system, it is necessary, first of all, to identify the main participants in the system and clearly define their activities and interaction scheme.

The main participants in the medical tourism system are:

- tour operator,

- travel agent,

- medical institution of initial examination and diagnosis,

- health resort institution or other medical institution.

Furthermore, it is essential to identify their key roles in the system.

A tour operator is engaged in the formation of a medical tourism product, its promotion, and direct sales during the trip.

A travel agent, being the main element of the sales network, promotes its capabilities to sell the medical tourism product developed by the tour operator and sells it directly to a prospective tourist.

A medical institution of initial examination and diagnosis implements the main objectives:

- prescription of the treatment program: the institution receives an application from the tour operator for treatment. After making the diagnosis, approving the advisory treatment plan and timing of its implementation, when medical tourists agree with the treatment, they are hospitalised and undergo prescribed medical and diagnostic procedures, consult with necessary specialists and discuss their treatment plans in a health resort;

- prescription of a diet and catering service, i. e, a medical institution ensures meals for medical tourists according to the prescription and the number of a diet;

- ensuring a comfortable stay of a patient at the institution, i. e., the conditions for the accommodation in the medical institution are discussed in advance; based on the needs and possibilities, a medical tourist chooses a room;

- prescription of the optimal day's routine, i. e, the doctor in charge prescribes the day's routine for a medical tourist's day which involves all medical procedures and recommendations related to medication and meals.

The major objectives of health resort institutions or other medical treatment institutions focus on:

- provision of high-quality medical measures prescribed by a hospital, i.e., medical measures are organised in the health resort according to the prescriptions of the attending doctor. All prescriptions are transferred to the attending physician in the health-resort institution; 
- provision of comfortable accommodation (various options for accommodation in patients' rooms are offered and medical tourists make their choice in advance);

- provision of meal, i.e., the health-resort provides a medical tourist with qualitative nourishment according to the prescription of a doctor in charge;

- carrying out of cultural events (developed by a tour-operator), i. e., within the staying at the health-resort and depending on their health state, medical tourists can take part in the events of cultural programme.

Such programmes can be tailored to the day's routine. Thus, medical tourists can take excursions and walking tours or participate in other events in their free time.

The mechanism of the interaction between the mentioned participants generally works as follows:

Tourists apply to a tour operator directly, or to a travel agent for medical examination (if necessary) in a certain medical institution, or they are offered the institution based on the profile of their illnesses, their preferences, and paying capacity. In cases where the tour operator organises the initial medical examination, the tourists are taken to the chosen medical institution.

Then the tourists interact with a consulting medical specialist, all the necessary medical and diagnostic procedures are conducted and a treatment programme and the terms of stay in the medical institution and later in the health resort are determined. Based on the accepted treatment programme, the clients are offered a medical tour that will be perfect for them. After that, the tourists are taken to the health-resort or other medical institution where they will receive the treatment according to the prescriptions (Fig. 1).

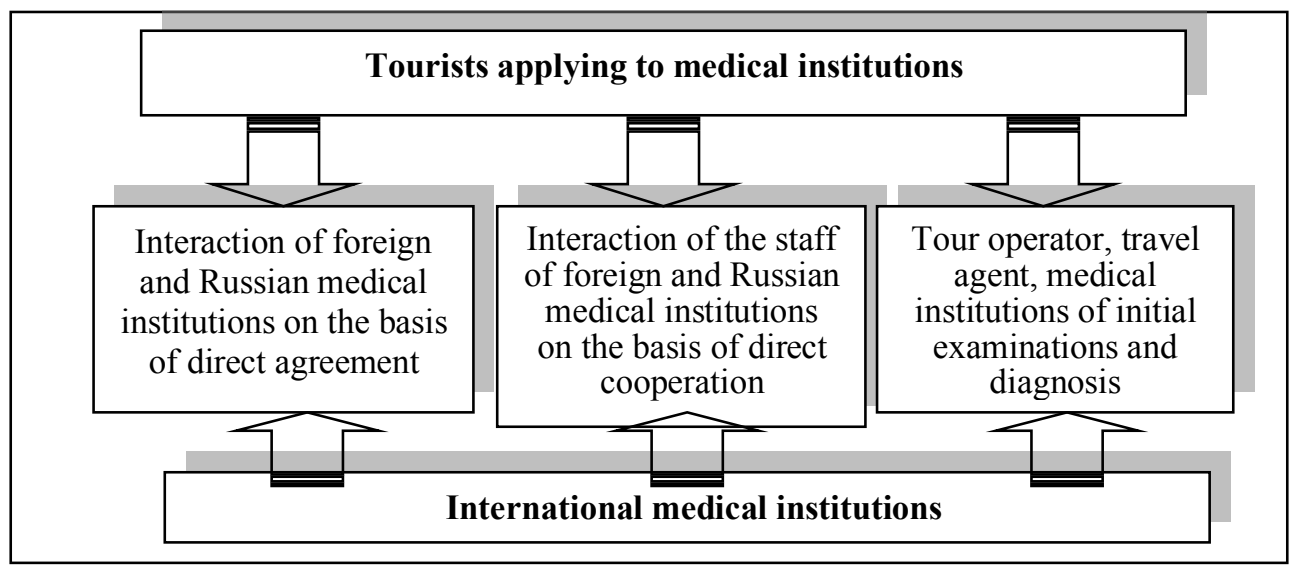

Fig. 1. Organisation of the interaction with foreign medical institutions.

In addition to the medical programme, the staying at the health-resort involves a cultural programme. Certainly, the participation depends on the medical tourists' health state. After completing the treatment course, the tourists return home [4].

So, there are three main business groups in the market that render the services in medical tourism [5]:

- international clinics

- agencies

- web aggregators or digital platforms including content marketing.

Content marketing is used on the platform to promote new trends of medical services. This helps develop trusting relationships with the target audience. Doctors join the direct discussions of diseases, treatment methods, and their prevention. This strengthens 
confidence in the organisation of a medical tour since the tourists see not just an information platform but a resource of highly qualified doctors.

The services rendered by the above-mentioned groups are classified by:

- location,

- principle of network,

- price range,

- profile of delivered services,

- mode to render services,

- distinctiveness of services.

Due to the activity breadth and geography of medical services, none of the areas has a clear leader. The companies that are supported by the government program have some advantage.

Figure 2 depicts the work scheme of medical tourism participants. As it can be seen from the scheme, all the participants work closely together thereby creating the optimal conditions for organising the entire process. Their clear interaction and differentiation of functions enable to create a high-quality product that will be in demand since it has the optimal ratio of medical treatment and recreation.

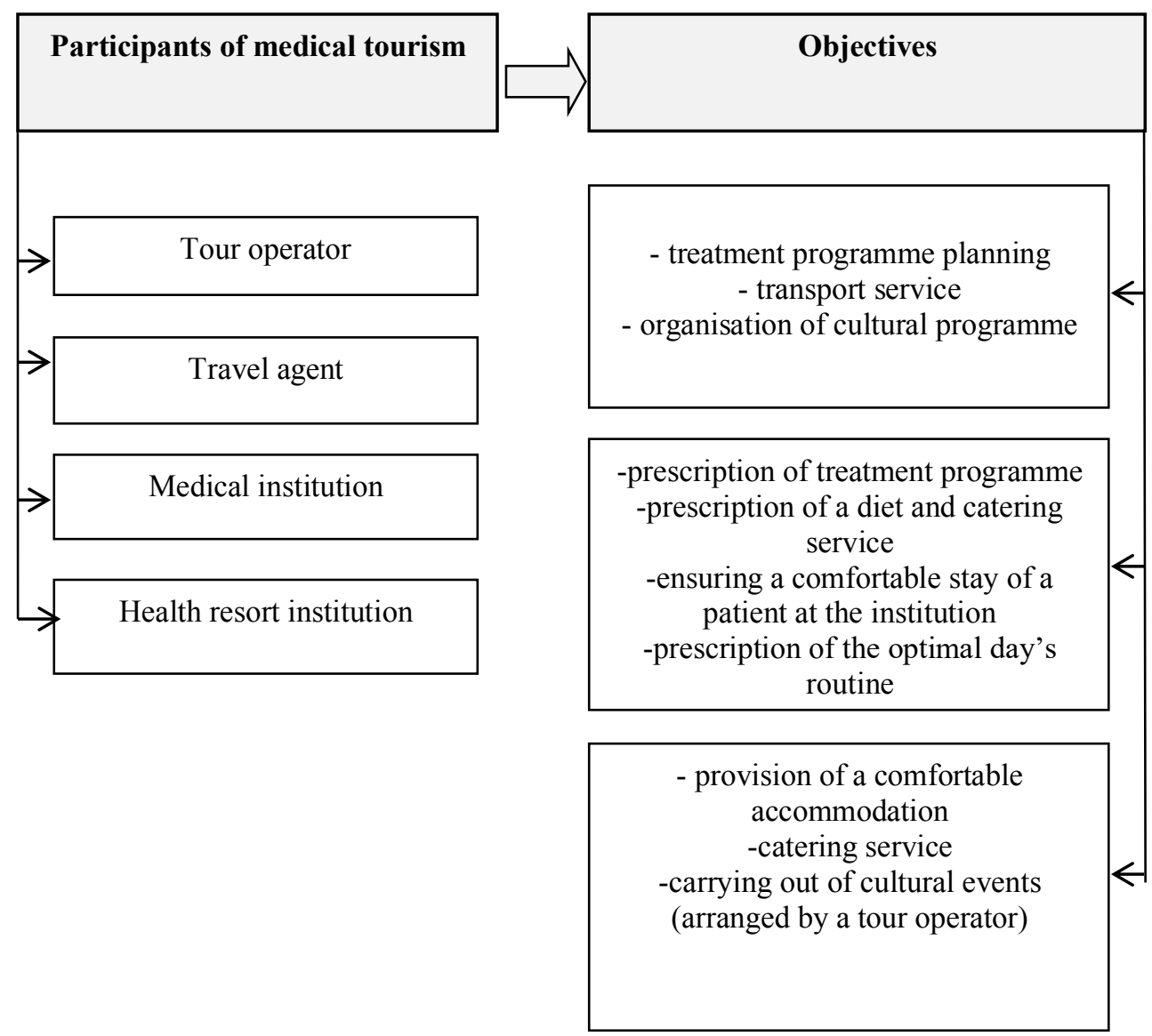

Fig. 2. Scheme of interaction of the main participants of medical tourism. 
The tourists receive medical services while their stay at a medical institution is of a short period (the most necessary treatment procedures are performed), the further treatment takes place in a more comfortable environment, where, besides the treatment, there is also a varied (as far as possible) programme of activities that allows tourists to distract from their health problems for some time, enjoy the rest, and get positive emotions which has a beneficial effect on their recovery.

Such a scheme of the interaction between the participants in the medical tourism system is basic, travel agencies specialising in medical tourism can be added to the system participants the function of which is to sell these packages to customers, help in choosing a medical institution, and render concierge services (booking of flights or train tickets, tourist escort, and translation/interpretation services (for foreign tourists).

Using this scheme of interaction between the participants in medical tourism, we can represent a system of medical tourism organisation in almost any region.

In order to further the development of medical tourism, it is possible to create a digital platform by applying artificial intelligence technologies (simplified analogue of AIRBNB service (impressions).

The medical institutions, providing the services to foreigners and non-resident citizens, will register on the digital platform. The portfolio of such organisation will contain a full range of medical services, information about doctors, accommodation during receiving the treatment, hotels and various services within walking distance. On the digital platform, tourists will be able to apply for a simplified procedure to obtain a visa, insurance policy, and, if necessary, apply for a loan.

To receive medical services, the patients will have to pass a unique identification on a digital platform. All patients' data will be saved on their personal accounts. The medical video-consultations with prospective doctors will be available on the account to make a final choice of clinic and medical service. The digital platform will provide integrated services. The integration of services with each other creates a unique system where everything is arranged and thought out in such a way as to meet all possible needs of patients in the best possible way.

Moreover, the digital platform is expected to include a complete professional support service for a patient, an open source software, a cloud storage, an analytical section for the marketing research in the field of medical tourism, the insurance of professional responsibility of a doctor and organisation, medical video-consultations when choosing a clinic and a prospective doctor, a simplified system for visa receiving as well as a financial model of e-commerce system of unique patient identification [5].

The creation of the digital platform for managing the medical tourism involves at the first stage the selection of priority areas for the provision of medical services to introduce them in the global medical market and the development of an appropriate business model. This is followed by the development of a set of insurance programmes for patients, the harmonisation of laws and regulations to ensure the unhindered admission of foreign patients, the development of logistics corridors, and the design of patient recruitment service programmes.

\section{References}

1. I. Arkharova, Medical tourism in Russia has grown more than twice (Web-site of the information group "TURPROM"). Retrieved on February 05, 2021, from https://www.tourprom.ru/news/37673/

2. Medical Tourism in Russia - there are prospects! Retrieved on February 05, 2021, from URL: $\quad$ http://smi.kodeks.ru/medicine/news/medicinskii-turizm-v-nbsp;rossii-nbsp;mdash;-est-perspektivy 
3. A. V. Egorkina, A. S. Yamshchikov, Trends of medical tourism development, Young researcher, 16, 47-49 (2019). Retrieved on February 09, 2021, from https://moluch.ru/archive/254/58188/

4. O. Chesnokova, $44 \%$ of foreign patients come to Russia to receive dental treatment (Vademecum) Retrieved on February 03, 2021 from https://vademec.ru/news/2020/02/03/44-inostrannykh-patsientov-edut-v-rossiyulechitzuby/

5. T. P. Levchenko, K. G. Ralko, Problems and prospects of medical tourism development, Bulletin of National Tourism Academy, 1(15), 17-20 (2020) 